\title{
Homelessness and Adherence to Antiretroviral Therapy among a Cohort of HIV-Infected Injection Drug Users
}

Anita Palepu, M-J Milloy, Thomas Kerr, Ruth Zhang, and Evan Wood

\begin{abstract}
Homelessness is prevalent among HIV-infected injection drug users (IDU) and may adversely affect access and adherence to antiretroviral therapy (ART). There are limited descriptions of the effect of homelessness on adherence to ART in long-term cohorts of HIV-infected IDU. We used data from a community-recruited prospective cohort of HIV-infected IDU, including comprehensive ART dispensation records, in a setting where HIV care is free. We examined the relationship between the homelessness measured longitudinally, and the odds of $\geq 95 \%$ adherence to ART using generalized estimating equations logistic regression modeling adjusting for sociodemographics, drug use, and clinical variables. Between May 1996 and September 2008, 545 HIV-infected IDU were recruited and eligible for the present study. The median follow-up duration was 23.8 months (IQR 8.5-91.6 months) contributing 2,197 person-years of follow-up. At baseline, homeless participants were slightly younger (35.8 vs. 37.9 years, $p=0.01)$ and more likely to inject heroin at least daily $(37.1 \%$ vs. $24.6 \% . p=0.004)$ than participants who had housing. The multivariate model revealed that homelessness (adjusted odds ratio [AOR] 0.66; 95\% CI: 0.53-0.84) and frequent heroin use (AOR 0.40; 95\% CI: 0.30-0.53) were significantly and negatively associated with ART adherence, whereas methadone maintenance was positively associated (AOR 2.33; 95\% CI: 1.86-2.92). Sub-optimal $A R T$ adherence was associated with homelessness and daily injection heroin use among HIV-infected IDU. Given the survival benefit of ART, it is critical to develop and evaluate innovative strategies such as supportive housing and methadone maintenance to address these risk factors to improve adherence.
\end{abstract}

KEYWORDS Homeless persons, HIV/AIDS, antiretroviral therapy, adherence

\section{INTRODUCTION}

Despite dramatic advances in antiretroviral therapy (ART) resulting in improved HIV treatment outcomes and survival, ${ }^{1-4}$ HIV-infected injection drug users (IDU) appear to have derived less benefit than other HIV-infected populations. ${ }^{5-7}$ There are a myriad of reasons ranging from barriers to accessing $\mathrm{ART}^{7,8}$ to decreased adherence due to ongoing substance use $\mathrm{e}^{9-12}$ and inadequate integration of addiction

Palepu, Kerr, and Wood are with the Department of Medicine, University of British Columbia, Vancouver, BC, Canada; Palepu is with the Centre for Health Outcomes and Evaluation Sciences, Vancouver, BC, Canada; Milloy and Wood are with the School of Population and Public Health, University of British Columbia, Vancouver, BC, Canada; Zhang is with the British Columbia Centre for Excellence in HIV/ AIDS, Vancouver, BC, Canada.

Correspondence: Anita Palepu, 620B-1081 Burrard Street, Vancouver, BC V6Z 1Y6, Canada. (E-mail: anita@hivnet.ubc.ca) 
treatment with HIV care. ${ }^{13-15}$ Another contributing factor may be the physical and social environments ${ }^{16,17}$ where a significant proportion of IDUs experience unstable housing or homelessness. ${ }^{18-20}$

Individuals who are unstably housed or homeless have a substantially increased HIV/AIDS infection rate compared to persons who are housed. ${ }^{21}$ Homeless persons also have higher risks of serious morbidity and mortality, with the most frequently reported causes of death being related to violence, HIV/AIDS, and substance misuse. ${ }^{22-26}$ Furthermore, homeless persons living with HIV have been found to be less likely to access and receive optimal regular HIV care. ${ }^{16,27-29}$ This may also related to healthcare associated barriers, given that prescribing physicians may be less likely to prescribe ART to these patients, although Bangsberg et al. ${ }^{30}$ demonstrated that providers inaccurately estimated ART adherence compared to structured patient report, which was more closely related to pill count among a sample of homeless or unstably housed HIV-infected persons.

Although homeless IDU have been reported to have lower rates of adherence to ART, active drug use and homelessness are states that can change over time and long-term evaluations of the impact of homelessness on adherence are limited and often conducted in settings with financial barriers to care. Unlike previous studies that have examined homelessness and HIV treatment adherence, the context of this study is one where HIV care is universally available and ART is provided at no charge. Thus, we used the data derived from a longstanding community-based cohort of HIV-infected IDU with detailed data on housing status and drug use behaviors to determine the longitudinal impact of homelessness on adherence to ART.

\section{METHODS}

Data for these analyses was derived from the AIDS Care Cohort to evaluate Exposure to Survival Services (ACCESS), an ongoing prospective observational cohort of HIV-infected illicit drug users in Vancouver, Canada. The methods for this study have been previously described. ${ }^{8,31,32}$ In brief, beginning in May 1996, participants were recruited through snowball sampling and extensive street outreach in the city's Downtown Eastside neighborhood, the local epicenter of drug-related HIV transmission. ACCESS eligibility criteria include: aged 18 years or older, HIVinfected, having used illicit drugs other than cannibinoids in the previous month, and having provided written informed consent. At baseline and every 6-month follow-up interview, participants answer a standardized interviewer-administered questionnaire, are examined by a study nurse and provide blood samples for serologic analysis. The information on sociodemographic, drug uses and other behavioral characteristics gathered at each interview is augmented with data on HIV care and treatment outcomes from the British Columbia Centre for Excellence in HIV/AIDS Drug Treatment Programme. This province-wide, centralized antiretroviral therapy dispensary and HIV/AIDS monitoring lab provides a complete prospective profile of CD4 cell counts, plasma HIV-1 RNA viral load, and dispensation of specific antiretroviral agents for each participant. ${ }^{8,31,32}$

\section{Measures}

In the present study, we included all participants who were HIV-infected who had a baseline CD4 count and viral load measurement. The primary outcome of interest was adherence to antiretroviral therapy. As in previous studies using this validated and confidential pharmacy dispensation data, ${ }^{32-34}$ we measured adherence to 
therapy in each 6-month period as a ratio of the number of days ART was dispensed over the number of days an individual was eligible for ART, and defined adherence as equal to or greater than $95 \%$ adherence to ART during this period. ${ }^{33}$ The clinical utility of this measure and its reliable prediction of virological suppression ${ }^{10,32-36}$ and survival ${ }^{32,33}$ has been previously shown. The primary explanatory variable, homelessness, was defined as living on the street or having no fixed address in the previous 6 months, which corresponded with the timeline of our primary outcome, ART adherence variable.

We also considered other explanatory variables that might confound the relationship between homelessness and ART adherence. These included demographic and socioeconomic characteristics such as age (per year older), gender (female vs. male), Aboriginal ancestry (yes vs. no), educational attainment $(<$ high school diploma vs. $\geq$ high school diploma), and legal employment (yes vs. no). Legal employment referred to having salaried or temporary work at any time in the previous 6 months. We also included the individual-level behavioral variables: injection cocaine use ( $\geq$ daily vs. $<$ daily), injection heroin use ( $\geq$ daily vs. $<$ daily), injection methamphetamine use ( $\geq$ daily vs. $<$ daily), and inhalation crack cocaine use ( $\geq$ daily vs. $<$ daily). We also included current use of methadone maintenance therapy. These variables were time-updated, referred to the 6-month period prior to the interview, and were consistent with previous analyses. ${ }^{32,37}$ Clinical variables included were the baseline CD4+ cell count (per 100 cells $/ \mathrm{mm}^{3}$ ) and HIV-1 RNA plasma viral load (per $\log _{10}$ ). For both measures, we used the mean of all available observations in the previous 6 months; if none were available, we used the most recent observation. Plasma HIV-1 RNA was measured using the Roche Amplicor Monitor assay (Roche Molecular Systems, Mississauga, Canada). We also included the year of the baseline interview to account for any cohort effects in ART prescribing.

\section{Statistical Analysis}

We first compared the baseline characteristics of the study sample stratified by homelessness, using the chi-squared test for categorical variables and the Wilcoxon rank-sum test for continuous variables. We then examined the bivariate relationships between adherence and all explanatory variables over the study period using generalized estimating equations logistic regression models employing an exchangeable working correlation matrix. ${ }^{38,39}$ This form of regression modeling was used to account for the correlation between covariates gathered over time from the same individual, and to estimate the independent effect of homelessness on the likelihood of adherence to ART within each individual. There were $93(17 \%)$ subjects who never accessed ART during the follow-up period and they were categorized as being non-adherent to ART. To account for possible confounding and calculate the best effect estimate, we constructed a multivariate model using an a priori defined modeling strategy suggested by Greenland et al. ${ }^{40}$ First, we fit a full model including the primary explanatory and all secondary explanatory variables. Using a manual stepwise approach, we constructed reduced models, each with one variable removed from the full set of secondary explanatory variables. Comparing the value of the coefficient for the primary explanatory in the full model and each of the reduced models, we removed the secondary explanatory corresponding to the smallest relative change. We continued this process until the maximum change from the full model exceeded 5\%. Several authors have successfully used this technique to 
estimate the independent relationship between an outcome of interest and a selected explanatory variable. ${ }^{40-42}$ We also examined selected interaction terms.

\section{RESULTS}

Between May 1996 and April 2008, there were 545 HIV-infected individuals who were eligible for the present study. The median follow-up duration was 23.8 months (IQR 8.5-91.6 months) contributing to 2,197 person-years of follow-up. The characteristics of participants who were homeless at baseline are presented in Table 1 . There were $143(26.2 \%)$ IDU who were homeless at baseline. There were no significant differences at baseline between the participants who were homeless and those who were not, other than that they were slightly younger (35.8 years vs. 37.9 years, $p=0.01$ ) and that they were more likely to inject heroin at least daily (37.1\% vs. $24.6 \%$. $p=0.004)$.

During the study period, there were $1,186(26.6 \%)$ observations that were $95 \%$ adherent, out of 4,460 total observations. Table 2 presents the bivariate association between each explanatory variable on ART adherence over the study period. Participants who were homeless were less likely to be adherent to ART (odds ratio [OR] 0.62; 95\% CI: 0.50-0.77). Female sex, lower educational attainment, frequent alcohol use, and injection drug use were negatively associated with ART adherence, whereas older age, methadone maintenance therapy, and time since the baseline interview were positively associated with adherence to ART.

The multivariate model result is depicted in Figure 1 and illustrates that after adjustment, homelessness (adjusted odds ratio [AOR] 0.66; 95\% CI: 0.53-0.84) and frequent heroin use (AOR 0.40;95\% CI: 0.30-0.53) were significantly and negatively associated with ART adherence adjusting for baseline CD4 count and baseline plasma viral load. Methadone maintenance therapy was positively associated with ART adherence (AOR 2.33; 95\% CI: 1.86-2.92). There were no significant interactions.

\section{DISCUSSION}

In this long-term prospective study of HIV-infected IDU, we found that homelessness and at least daily heroin use were negatively associated with ART adherence, whereas methadone maintenance was positively associated with adherence to ART. It has been previously shown that HIV-infected IDU who are able to achieve the $95 \%$ level of adherence derive the clinical benefits of treatment through HIV-1 RNA viral suppression and CD4 cell count rise. ${ }^{10,43}$

A number of studies have also found that ART adherence is negatively associated with ongoing drug use..$^{9,11,12,36}$ These studies have emphasized the importance of addressing addiction issues for HIV-infected IDU to optimize HIV treatment outcomes. Lucas et al. ${ }^{44}$ recently reported a small randomized controlled trial comparing clinic-based buprenorphine-naloxone (BUP) versus off-site referral for opiate treatment for HIV-infected opioid-dependent patients and found that integrating BUP in the clinic setting increased access to addiction treatment and improved substance abuse treatment outcomes. Methadone maintenance therapy has also been shown to improve ART adherence and HIV treatment outcomes in variety of settings. $34,37,45,46$

Homelessness in and of itself represents a significant structural risk factor for increased morbidity and mortality, ${ }^{22,23,25,47}$ and for HIV-infected drug and alcohol 
TABLE 1 Selected sociodemographic, behavioral, and clinical characteristics at baseline, stratified by homelessness in ACCESS ( $n=545$ participants)

\begin{tabular}{|c|c|c|c|c|c|}
\hline \multirow[b]{3}{*}{ Characteristic } & \multicolumn{2}{|l|}{ Homelessness } & \multirow[b]{3}{*}{$\mathrm{OR}^{\mathrm{a}}$} & \multirow[b]{3}{*}{$95 \% \mathrm{Cl}^{\mathrm{b}}$} & \multirow[b]{3}{*}{$p$ Value } \\
\hline & Yes & No & & & \\
\hline & $143(26.2)$ & $402(73.8)$ & & & \\
\hline \multicolumn{6}{|l|}{ Age } \\
\hline Median (IQR) & $35.8(29.1-42.3)$ & $37.9(31.8-43.9)$ & 0.97 & $0.95-0.99$ & 0.01 \\
\hline \multicolumn{6}{|l|}{ Gender } \\
\hline Male & 95 (66.4) & $246(61.2)$ & 1.00 & & \\
\hline Female & 48 (33.6) & 156 (38.8) & 0.80 & $0.53-1.19$ & 0.266 \\
\hline \multicolumn{6}{|l|}{ Aboriginal ancestry } \\
\hline No & $96(67.1)$ & $264(65.7)$ & 1.00 & & \\
\hline Yes & $47(32.9)$ & $138(34.4)$ & 0.94 & $0.62-1.40$ & 0.751 \\
\hline \multicolumn{6}{|l|}{ Educational attainment } \\
\hline$\geq$ High school diploma & $124(86.7)$ & $345(85.8)$ & 1.00 & & \\
\hline$<$ High school diploma & $19(13.3)$ & $57(14.2)$ & 0.93 & $0.53-1.62$ & 0.791 \\
\hline \multicolumn{6}{|l|}{ Formal employment } \\
\hline No & $115(80.4)$ & $350(87.1)$ & 1.00 & & \\
\hline Yes & $28(19.6)$ & $52(12.9)$ & 1.64 & $0.99-2.72$ & 0.054 \\
\hline \multicolumn{6}{|l|}{ Frequent alcohol use } \\
\hline$<$ Daily & $129(90.2)$ & $348(86.6)$ & 1.00 & & \\
\hline$\geq$ Daily & $14(9.8)$ & $54(13.4)$ & 0.70 & $0.38-1.30$ & 0.258 \\
\hline \multicolumn{6}{|l|}{ Frequent crack cocaine use } \\
\hline$<$ Daily & $100(69.9)$ & $313(77.9)$ & 1.00 & & \\
\hline$\geq$ Daily & $43(30.1)$ & $89(22.1)$ & 1.51 & $0.99-2.32$ & 0.06 \\
\hline \multicolumn{6}{|l|}{ Frequent cocaine injection } \\
\hline$<$ Daily & $92(64.3)$ & $261(4.9)$ & 1.00 & & \\
\hline$\geq$ Daily & $51(35.7)$ & 141 (35.1) & 1.03 & $0.69-1.53$ & 0.899 \\
\hline \multicolumn{6}{|l|}{ Frequent heroin injection } \\
\hline$<$ Daily & $90(62.9)$ & $303(75.4)$ & 1.00 & & \\
\hline$\geq$ Daily & $53(37.1)$ & $99(24.6)$ & 1.80 & $1.20-2.71$ & 0.004 \\
\hline \multicolumn{6}{|l|}{ Frequent speedball injection } \\
\hline$<$ Daily & $123(86.0)$ & $344(85.6)$ & 1.00 & & \\
\hline$\geq$ Daily & $20(14)$ & $58(14.4)$ & 0.96 & $0.56-1.67$ & 0.897 \\
\hline \multicolumn{6}{|l|}{ Frequent crystal meth injection } \\
\hline$<$ Daily & $140(97.9)$ & $395(98.3)$ & 1.00 & & \\
\hline$\geq$ Daily & $3(2.1)$ & $7(1.7)$ & 1.21 & $0.31-4.74$ & 0.727 \\
\hline \multicolumn{6}{|c|}{ Current methadone maintenance therapy } \\
\hline No & $100(69.9)$ & $276(68.7)$ & 1.00 & & \\
\hline Yes & $43(30.1)$ & $126(31.3)$ & 0.94 & $0.62-1.42$ & 0.777 \\
\hline \multicolumn{6}{|l|}{ CD4+ cell count } \\
\hline Median (IQR) 100 cells/mm3 & $3.5(2.1-5.3)$ & $3.4(2.1-4.7)$ & 1.04 & $0.96-1.12$ & 0.532 \\
\hline \multicolumn{6}{|l|}{ HIV-1 RNA viral load } \\
\hline Median (IQR) per log10 & $4.3(2.9-4.9)$ & $4.2(2.6-4.8)$ & 1.06 & $0.92-1.23$ & 0.472 \\
\hline
\end{tabular}

${ }^{\text {a }}$ Odds ratio

${ }^{b} 95 \%$ Confidence interval

users who are homeless, their existing vulnerabilities are further heightened. ${ }^{48}$ Homelessness among HIV-infected IDU may affect ART adherence through a multitude of mechanisms, including poor access to regular meals and water, lack of a fixed daily routine, no place to store the medication, lack of privacy, and stigma, as 
TABLE 2 Bivariate GEE logistic regression analysis of explanatory variables and ART adherence in ACCESS ( $n=545$ participants contributed to 4,460 observations)

\begin{tabular}{|c|c|c|c|}
\hline Characteristic & $O R^{a}$ & $95 \% \mathrm{Cl}^{\mathrm{b}}$ & $p$ Value \\
\hline \multicolumn{4}{|l|}{ Homelessness $^{c}$} \\
\hline No & 1.00 & & \\
\hline Yes & 0.62 & $0.50-0.77$ & $<0.001$ \\
\hline \multicolumn{4}{|l|}{ Age } \\
\hline (per year) & 1.06 & $1.04-1.08$ & $<0.001$ \\
\hline \multicolumn{4}{|l|}{ Gender } \\
\hline Male & 1.00 & & \\
\hline Female & 0.69 & $0.52-0.89$ & 0.006 \\
\hline \multicolumn{4}{|l|}{ Aboriginal ancestry } \\
\hline No & 1.00 & & \\
\hline Yes & 0.97 & $0.74-1.28$ & 0.84 \\
\hline \multicolumn{4}{|l|}{ Formal employment $^{c}$} \\
\hline No & 1.00 & & \\
\hline Yes & 1.11 & $0.87-1.41$ & 0.40 \\
\hline \multicolumn{4}{|l|}{ Educational attainment } \\
\hline$\geq$ High school diploma & 1.00 & & \\
\hline$<$ High school diploma & 0.56 & $0.37-0.85$ & 0.007 \\
\hline \multicolumn{4}{|l|}{ Frequent alcohol use $\mathrm{c}^{\mathrm{c}}$} \\
\hline$<$ Daily & 1.00 & & \\
\hline$\geq$ Daily & 0.64 & $0.47-0.86$ & 0.004 \\
\hline \multicolumn{4}{|c|}{ Frequent crack cocaine use $\mathrm{e}^{\mathrm{c}}$} \\
\hline$<$ Daily & 1.00 & & \\
\hline$\geq$ Daily & 0.94 & $0.78-1.13$ & 0.51 \\
\hline \multicolumn{4}{|c|}{ Frequent cocaine use, injection ${ }^{c}$} \\
\hline$<$ Daily & 1.00 & & \\
\hline$\geq$ Daily & 0.48 & $0.40-0.57$ & $<0.001$ \\
\hline \multicolumn{4}{|c|}{ Frequent heroin use, injection ${ }^{c}$} \\
\hline$<$ Daily & 1.00 & & \\
\hline$\geq$ Daily & 0.38 & $0.30-0.48$ & $<0.001$ \\
\hline \multicolumn{4}{|c|}{ Frequent speedball use, injection ${ }^{c}$} \\
\hline$<$ Daily & 1.00 & & \\
\hline$\geq$ Daily & 0.34 & $0.25-0.48$ & $<0.001$ \\
\hline \multicolumn{4}{|c|}{ Frequent methamphetamine use, injection ${ }^{c}$} \\
\hline$<$ Daily & 1.00 & & \\
\hline$\geq$ Daily & 0.70 & $0.44-1.14$ & 0.15 \\
\hline \multicolumn{4}{|c|}{ Methadone maintenance therapy } \\
\hline No & 1.00 & & \\
\hline Yes & 2.44 & $2.01-2.96$ & $<0.001$ \\
\hline \multicolumn{4}{|l|}{ CD4 cell count } \\
\hline Per 100 cells $/ \mathrm{mm}^{3}$ & 0.94 & $0.89-0.99$ & 0.047 \\
\hline Per $\log 10$ unit increase & 0.54 & $0.48-0.60$ & $<0.001$ \\
\hline
\end{tabular}

GEE generalized estimating equations

adds ratio

${ }^{\mathrm{b}} 95 \%$ Confidence interval

${ }^{\mathrm{c}}$ Refers to the 6-month period prior to the interview 


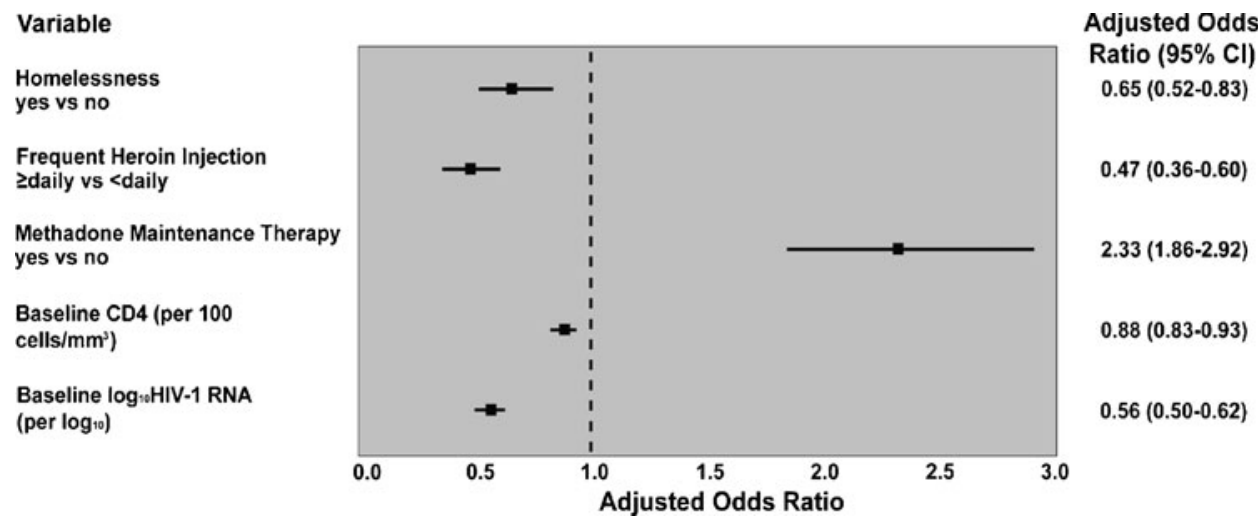

FIGURE 1. Multivariable logistic regression model using GEE of factors associated with $95 \%$ antiretroviral therapy adherence.

well as concomitant psychiatric disorders. ${ }^{15}$ Given the complexity of managing their health, it is not surprising that case management has been shown to be positively associated with ART adherence and improved HIV treatment outcomes among homeless HIV-infected persons. ${ }^{49}$

Directly administered ART or modified directly observed ART administration among HIV-infected IDU or persons with substance dependence have been evaluated in randomized trials and have found improved adherence and HIV treatment outcomes. ${ }^{50-53}$ One study followed patients after the directly administered ART intervention when they went to self-administration and found no difference in viral suppression at 6 months after the end of the trial, suggesting that ongoing strategies are required to maintain the initial benefit. ${ }^{54}$

A focus on individual-level behaviors alone may not be effective in improving ART adherence, especially in the context of homelessness or unstable housing. Strategies that address broader determinants of health, such as housing, for this vulnerable group are more likely to be effective in creating the social and physical environments that reduce the ongoing risks for non-adherence and other HIV-risk behavior. ${ }^{16,55}$ The Housing and Health randomized trial of the effects of Housing Opportunities for People with AIDS rental assistance on the health and risk behavior of homeless and unstably housed HIV-infected persons was recently reported. ${ }^{56}$ They noted a significant increase in stable housing status over time for both the intervention and control group; however, it was higher for the intervention group at 18 months $(82.5 \%$ vs. $50.6 \%, p<0.0001)$. In terms of health outcomes, there was no difference between groups in the proportion non-adherent to ART or new uptake of ART. The intervention group reported more appropriate medical care, had better mental and physical health scores, and lower stress than the control group. ${ }^{56}$ The power to detect differences between groups was attenuated by the higher-thanexpected movement into housing among the control group in this trial. In contrast, the Chicago Housing for Health Partnership randomized trial examined the effect of a housing and case management program for hospitalized homeless persons with HIV who were ready for discharge, and found that more of the intervention group were alive after 12 months and had CD 4 counts $\geq 200$ cells/ $\mathrm{mm}^{3}(55 \%$ vs. $34 \%, p=0.04)$. Unfortunately, they do not report on ART medication adherence. ${ }^{57}$ The housing model used in this study was "Housing First" 58,59 and there were no sobriety or treatment adherence requirements for the participants, unlike housing ready models. 
Our study had limitations. The cohort was not a random sample of HIVinfected participants and this is not feasible as no registry of all HIV-infected individuals, particularly illicit drug users, exists. This may limit the generalizability of our results to other settings. Our pharmacy refill measure may be an overestimation of adherence in our sample as we do not know if the study participants ingested their medication, although the measure has proven to be a potent predictor of virologic suppression and mortality among HIV-infected persons. ${ }^{32-34}$

In summary, we found that over a quarter of our HIV-infected IDU were homeless at baseline and that in our longitudinal analysis, homelessness and frequent heroin use were negatively associated with ART adherence. Only methadone maintenance was positively associated with adherence. Given the high morbidity and mortality associated with sub-optimal ART adherence, future studies should evaluate innovative interventions that strengthen the links between supportive housing and addiction treatment for HIV-infected IDU.

\section{ACKNOWLEDGMENTS}

The authors thank the study participants for their contribution to the research as well as current and past researchers and staff. We would specifically like to thank Deborah Graham, Tricia Collingham, Caitlin Johnston, and Steve Kain for their research and administrative assistance, and Drs. Julio Montaner and Robert Hogg for facilitating access to the British Columbia Centre for Excellence HIV/AIDS Drug Treatment Program data. The study was supported by the US National Institutes of Health (R01DA021525) and the Canadian Institutes of Health Research (MOP79297, RAA-79918). Thomas Kerr is supported by the Michael Smith Foundation for Health Research and the Canadian Institutes of Health Research (CIHR). M-J Milloy is supported by a doctoral research award from CIHR.

Human participant protection. The ACCESS cohort is reviewed annually and has been approved by the University of British Columbia/Providence Healthcare Research Ethics Board.

Funding support. The study was supported by the US National Institutes of Health (R01DA021525) and the Canadian Institutes of Health Research (MOP-79297, RAA-79918).

OPEN ACCESS This article is distributed under the terms of the Creative Commons Attribution Noncommercial License which permits any noncommercial use, distribution, and reproduction in any medium, provided the original author(s) and source are credited.

\section{REFERENCES}

1. Hammer SM, Squires KE, Hughes MD, et al. A controlled trial of two nucleoside analogues plus indinavir in persons with human immunodeficiency virus infection and CD 4 cell counts of 200 per cubic millimeter or less. AIDS Clinical Trials Group 320 Study Team. NEJM. 1997; 337(11): 725-33.

2. Mocroft A, Ledergerber B, Katlama C, et al. Decline in the AIDS and death rates in the EuroSIDA study: an observational study. Lancet. 2003; 362(9377): 22-9. 
3. Hogg RS, Yip B, Chan KJ, et al. Rates of disease progression by baseline CD4 cell count and viral load after initiating triple-drug therapy. JAMA. 2001; 286(20): 2568-77.

4. Palella FJ Jr, Delaney KM, Moorman AC, et al. Declining morbidity and mortality among patients with advanced human immunodeficiency virus infection. HIV Outpatient Study Investigators. NEJM. 1998; 338(13): 853-60.

5. Vlahov D, Celentano DD. Access to highly active antiretroviral therapy for injection drug users: adherence, resistance, and death. Cad Saúde Pública. 2006; 22(4): 705-18.

6. Lert F, Kazatchkine MD. Antiretroviral HIV treatment and care for injecting drug users: an evidence-based overview. Int J Drug Policy. 2007; 18(4): 255-61.

7. Wood E, Montaner JSG, Tyndall MW, Schechter MT, O'Shaughnessy MV, Hogg RS. Prevalence and correlates of untreated human immunodeficiency virus type 1 infection among persons who have died in the era of modern antiretroviral therapy. J Infect Dis. 2003; 188(8): 1164-70.

8. Strathdee SA, Palepu A, Cornelisse PG, et al. Barriers to use of free antiretroviral therapy in injection drug users. JAMA. 1998; 280(6): 547-9.

9. Lucas GM, Griswold M, Gebo KA, Keruly J, Chaisson RE, Moore RD. Illicit drug use and HIV-1 disease progression: a longitudinal study in the era of highly active antiretroviral therapy. Am J Epidemiol. 2006; 163(5): 412-20.

10. Wood E, Montaner JS, Yip B, et al. Adherence and plasma HIV RNA responses to highly active antiretroviral therapy among HIV-1 infected injection drug users. CMAJ. 2003; 169(7): 656-61.

11. Lucas GM, Gebo KA, Chaisson RE, Moore RD. Longitudinal assessment of the effects of drug and alcohol abuse on HIV-1 treatment outcomes in an urban clinic. AIDS. 2002; 16 (5): 767-74.

12. Lucas GM, Cheever LW, Chaisson RE, Moore RD. Detrimental effects of continued illicit drug use on the treatment of HIV-1 infection. J Acquir Immune Defic Syndr. 2001; 27(3): 251-9.

13. Krusi A, Wood E, Montaner J, Kerr T. Social and structural determinants of HAART access and adherence among injection drug users. Int J Drug Policy. 2010; 21(1): 4-9.

14. Wood E, Kerr T, Tyndall MW, Montaner JS. A review of barriers and facilitators of HIV treatment among injection drug users. AIDS. 2008; 22(11): 1247-56.

15. Douaihy AB, Stowell KR, Bui T, Daley D, Salloum I. HIV/AIDS and homelessness, part 2: treatment issues. AIDS Read. 2005; 15(11): 604-18.

16. Wolitski RJ, Kidder DP, Fenton KA. HIV, homelessness, and public health: critical issues and a call for increased action. AIDS Behav. 2007; 11(6 Suppl): 167-71.

17. Galea S, Rudenstine S, Vlahov D. Drug use, misuse, and the urban environment. Drug Alcohol Rev. 2005; 24(2): 127-36.

18. Kim C, Kerr T, Li K, et al. Unstable housing and hepatitis $\mathrm{C}$ incidence among injection drug users in a Canadian setting. BMC Public Health. 2009; 9(1): 270.

19. Palepu A, Strathdee SA, Hogg RS, et al. The social determinants of emergency department and hospital use by injection drug users in Canada. J Urban Health. 1999; 76(4): 409-18.

20. Strathdee SA, Patrick DM, Currie SL, et al. Needle exchange is not enough: lessons from the Vancouver injecting drug use study. AIDS. 1997; 11(8): F59-65.

21. Culhane DP, Gollub E, Kuhn R, Shpaner M. The co-occurrence of AIDS and homelessness: results from the integration of administrative databases for AIDS surveillance and public shelter utilisation in Philadelphia. J Epidemiol Community Health. 2001; 55(7): 515-20.

22. Hwang SW. Mortality among men using homeless shelters in Toronto, Ontario. JAMA. 2000; 283(16): 2152-7.

23. Hwang SW, Lebow JM, Bierer MF, O’Connell JJ, Orav EJ, Brennan TA. Risk factors for death in homeless adults in Boston. Arch Intern Med. 1998; 158(13): 1454-60.

24. Hwang SW, Orav EJ, O'Connell JJ, Lebow JM, Brennan TA. Causes of death in homeless adults in Boston. Ann Intern Med. 1997; 126(8): 625-8. 
25. Cheung AM, Hwang SW. Risk of death among homeless women: a cohort study and review of the literature. CMAJ. 2004; 170(8): 1243-7.

26. Morrison DS. Homelessness as an independent risk factor for mortality: results from a retrospective cohort study. Int J Epidemiol. 2009; 38(3): 877-83.

27. Aidala AA, Lee G, Abramson DM, Messeri P, Siegler A. Housing need, housing assistance, and connection to HIV medical care. AIDS Behav. 2007; 11(6 Suppl): 101-15.

28. Leaver CA, Bargh G, Dunn JR, Hwang SW. The effects of housing status on healthrelated outcomes in people living with HIV: a systematic review of the literature. AIDS Behav. 2007; 11(6 Suppl): 85-100.

29. Kidder DP, Wolitski RJ, Campsmith ML, Nakamura GV. Health status, health care use, medication use, and medication adherence among homeless and housed people living with HIV/AIDS. Am J Public Health. 2007; 97(12): 2238-45.

30. Bangsberg DR, Hecht FM, Clague H, et al. Provider assessment of adherence to HIV antiretroviral therapy. J Acquir Immune Defic Syndr. 2001; 26(5): 435-42.

31. Wood E, Hogg RS, Bonner S, et al. Staging for antiretroviral therapy among HIV-infected drug users. JAMA. 2004; 292(10): 1175-7.

32. Wood E, Hogg RS, Lima VD, et al. Highly active antiretroviral therapy and survival in HIV-infected injection drug users. JAMA. 2008; 300(5): 550-4.

33. Wood E, Hogg RS, Yip B, et al. Effect of medication adherence on survival of HIVinfected adults who start highly active antiretroviral therapy when the CD4+ cell count is 0.200 to $0.350 \times 10$ (9) cells/L. Ann Intern Med. 2003; 139(10): 810-6.

34. Palepu A, Tyndall MW, Joy R, et al. Antiretroviral adherence and HIV treatment outcomes among HIV/HCV co-infected injection drug users: the role of methadone maintenance therapy. Drug Alcohol Depend. 2006; 84(2): 188-94.

35. Low-Beer S, Yip B, O'Shaughnessy MV, Hogg RS, Montaner JS. Adherence to triple therapy and viral load response. J Acquir Immune Defic Syndr. 2000; 23(4): 360-1.

36. Palepu A, Tyndall M, Yip B, O'Shaughnessy MV, Hogg RS, Montaner JS. Impaired virologic response to highly active antiretroviral therapy associated with ongoing injection drug use. J Acquir Immune Defic Syndr. 2003; 32(5): 522-6.

37. Uhlmann S, Milloy MJ, Kerr T, et al. Methadone maintenance therapy promotes initiation of antiretroviral therapy among injection drug users. Addiction. 2010; 105(5): 907-13.

38. Zeger SL, Liang KY. Longitudinal data analysis for discrete and continuous outcomes. Biometrics. 1986; 42: 121-30.

39. Liang KY, Zeger SY. Longitudinal data analysis using generalized linear models. Biometrika. 1986; 73: 13-22.

40. Maldonado G, Greenland S. Simulation study of confounder-selection strategies. Am J Epidemiol. 1993; 138(11): 923-36.

41. Marshall BD, Kerr T, Shoveller JA, Patterson TL, Buxton JA, Wood E. Homelessness and unstable housing associated with an increased risk of HIV and STI transmission among street-involved youth. Health Place. 2009; 15(3): 753-60.

42. Lima V, Fernandes K, Rachlis B, Druyts E, Montaner J, Hogg R. Migration adversely affects antiretroviral adherence in a population-based cohort of HIV/AIDS patients. Soc Sci Med. 2009; 68(6): 1044-9.

43. Wood E, Montaner JS, Yip B, et al. Adherence to antiretroviral therapy and CD4 T-cell count responses among HIV-infected injection drug users. Antivir Ther. 2004; 9(2): 22935 .

44. Lucas GM, Chaudhry A, Hsu J, et al. Clinic-based treatment of opioid-dependent HIVinfected patients versus referral to an opioid treatment program: a randomized trial. Ann Intern Med. 2010; 152(11): 704-11.

45. Avants SK, Margolin A, Warburton LA, Hawkins KA, Shi J. Predictors of nonadherence to HIV-related medication regimens during methadone stabilization. Am J Addict American. 2001; 10(1): 69-78. 
46. Palepu A, Horton NJ, Tibbetts N, Meli S, Samet JH. Uptake and adherence to highly active antiretroviral therapy among HIV-infected people with alcohol and other substance use problems: the impact of substance abuse treatment. Addiction. 2004; 99 (3): 361-8.

47. Hwang SW, O'Connell JJ, Lebow JM, Bierer MF, Orav EJ, Brennan TA. Health care utilization among homeless adults prior to death. J Health Care Poor Underserved. 2001; 12(1): 50-8.

48. Walley AY, Cheng DM, Libman H, et al. Recent drug use, homelessness and increased short-term mortality in HIV-infected persons with alcohol problems. AIDS. 2008; 22(3): 415-20.

49. Kushel MB, Colfax G, Ragland K, Heineman A, Palacio H, Bangsberg DR. Case management is associated with improved antiretroviral adherence and CD4+ cell counts in homeless and marginally housed individuals with HIV infection. Clin Infect Dis. 2006; 43(2): 234-42.

50. Macalino GE, Hogan JW, Mitty JA, et al. A randomized clinical trial of community-based directly observed therapy as an adherence intervention for HAART among substance users. AIDS. 2007; 21(11): 1473-7.

51. Tyndall MW, McNally M, Lai C, et al. Directly observed therapy programmes for antiretroviral treatment amongst injection drug users in Vancouver: access, adherence and outcomes. Int J Drug Policy. 2007; 18(4): 281-7.

52. Altice FL, Maru DS, Bruce RD, Springer SA, Friedland GH. Superiority of directly administered antiretroviral therapy over self-administered therapy among HIV-infected drug users: a prospective, randomized, controlled trial. Clin Infect Dis. 2007; 45(6): 7708.

53. Conway B, Prasad J, Reynolds R, et al. Directly observed therapy for the management of HIV-infected patients in a methadone program. Clin Infect Dis. 2004; 38(Suppl 5): S4028.

54. Maru DS, Bruce RD, Walton M, Springer SA, Altice FL. Persistence of virological benefits following directly administered antiretroviral therapy among drug users: results from a randomized controlled trial. J Acquir Immune Defic Syndr. 2009; 50(2): 176-81.

55. Kidder DP, Wolitski RJ, Royal S, et al. Access to housing as a structural intervention for homeless and unstably housed people living with HIV: rationale, methods, and implementation of the housing and health study. AIDS Behav. 2007; 11(6 Suppl): 14961.

56. Wolitski RJ, Kidder DP, Pals SL, et al. Randomized trial of the effects of housing assistance on the health and risk behaviors of homeless and unstably housed people living with HIV. AIDS Behav. 2010; 14(3): 493-503.

57. Buchanan D, Kee R, Sadowski LS, Garcia D. The health impact of supportive housing for HIV-positive homeless patients: a randomized controlled trial. Am J Public Health. 2009; 99(Suppl 3): S675-80.

58. Culhane D, Metraus S, Hadley T. Public service reductions associated with placement of homeless persons with severe mental illness in supportive housing. Hous Policy Debate. 2002; 13: 107-62.

59. Tsemberis S, Gulcur L, Nakae M. Housing First, consumer choice, and harm reduction for homeless individuals with a dual diagnosis. Am J Public Health. 2004; 94(4): 651-6. 